\title{
Análise morfométrica de microbacias hidrográficas, comparando a cartografia na escala 1:10.000 e a medida de campo, Batatais, SP.
}

\author{
Marcelo Zanata ${ }^{1}$ \\ Teresa Cristina Tarlé Pissarra ${ }^{2}$ \\ Sergio Campos ${ }^{3}$ \\ ${ }^{1}$ Instituto Florestal - IF/SMA \\ Caixa Postal 68 - 14300-000 - Batatais - SP, Brasil \\ marcel_zanata@netsite.com.br \\ ${ }^{2}$ UNESP, Campus de Jaboticabal \\ Via de acesso Prof. Paulo Donato Castellane s/n - 14870-000- Jaboticabal, SP, Brasil \\ teresap@fcav.unesp.br \\ ${ }^{3}$ UNESP, Campus de Botucatu \\ Fazenda Experimental Lageado - 18603-970 - Botucatu, SP, Brasil \\ sergioc@fca.unesp.br
}

\begin{abstract}
In order to conduct a physical analysis of watersheds and by comparing the maps in 1:10,000 scale and extent of field. Situated between the geographical coordinates $20^{\circ} 53^{\prime} 35^{\circ}$ "to $20^{\circ} 57^{\prime} 54^{\prime \prime} \mathrm{N}$ Latitude and $47^{\circ}$ $31^{\prime} 45^{\prime \prime}$ to $47^{\circ} 33 \prime 21^{\prime \prime} \mathrm{W}$. longitude Gr, the watershed is characterized as an exoreic fluvial drainage with consequent streams and dendrite drainage. The values of drainage density, frequency of rivers and bifurcation ratio are considered low, indicating the formation of permeable soil over rock, with less superficial tendency to runoff and more increased water infiltration into soil. The extent field data has not changed its classification of $4^{\text {th }}$ magnitude, but changed the number of compartments of the hydrological basins of $1^{\text {st }}$ and ${ }^{2 \text { nd }}$ orders, and increased the length of the drainage network.
\end{abstract}

Palavras-chave: analise morfométrica, microbacia hidrográfica, medida de campo.

\section{Introdução}

Em trabalhos de cartografia é necessário indicar a proporção entre a superfície terrestre e a sua representação. Essa proporção é indicada pela escala, a qual representa a relação entre a medida de uma porção territorial representada no papel e sua medida real na superfície terrestre.

No início do século XX, os estudos de Horton (1945) e Strahler (1957) definem a hierarquia fluvial, considerando as nascentes e seus cursos d'água, de acordo com o número de afluentes de cada bacia hidrográfica. Sendo assim, a cartografia da rede de drenagem respectivas curvas de nível é de extrema importância para análise morfométrica do terreno.

A morfometria da microbacia hidrográfica é importante ferramenta de diagnóstico da suscetibilidade à degradação ambiental. Seus resultados norteiam o planejamento, o manejo e a implementação de medidas mitigadoras para a conservação dos recursos naturais (RODRIGUES, 2003). A análise morfométrica é o exame in situ das propriedades do solo e de suas relações com o relevo, vegetação, material de origem e clima (FREIRE, 2006).

O presente trabalho tem por objetivo calcular, analisar as características morfométricas dimensionais, do padrão da rede de drenagem e do relevo da microbacia do Córrego da Cachoeira, Município de Batatais, SP, comparando os dados da cartografia na escala 1:10.000 e a medida de campo. 


\section{Material e Métodos}

Localizada no Município de Batatais, a microbacia hidrográfica do Córrego da Cachoeira está situada entre as coordenadas geográficas $20^{\circ} 53$ '35" a $20^{\circ} 57^{\prime} 54^{\prime \prime}$ de Latitude S


mesotérmico úmido de verão quente ( $\mathrm{Cwa})$, com temperatura média do mês mais quente superior a $22^{\circ} \mathrm{C}$. A precipitação varia entre 1.100 e $1.700 \mathrm{~mm}$ anuais.

Sua formação geológica é de rochas efusivas básicas da Formação Serra Geral e areias não consolidadas de origem mais recente, provavelmente do cenozóico, que recobrem as rochas efusivas básicas em parte da área (SÃO PAULO, 1981). No Sistema Brasileiro de Classificação de Solos (CAMARGO e KAUFMANN, 1987) são classificadas como Latossolo Vermelho-Amarelo, textura média.

A base cartográfica do Instituto Geográfico e Cartográfico (IGC) na escala 1:10.000, folhas SF-23-V-A-IV-4: (SO-B) Capão Grande, (SE-A) Batatais, (SE-B) Fazenda Esteio, (SO-D) Ribeirão da Mata, (SE-C) Córrego da Prata, (SE-D) Chácara Caiapós, (SO-F) Brodowski, (SE-E) Córrego Olhos D’água (SÃO PAULO, 1992) foi utilizada para a classificação de sua rede de drenagem e das respectivas microbacias hidrográficas, de acordo com o sistema de Horton (1945), modificado por Strahler (1957).

Para a coleta de dados físicos de cada sub-bacia de $1^{\mathrm{a}}, 2^{\mathrm{a}}, 3^{\mathrm{a}}$ e $4^{\mathrm{a}}$ ordens o software AutoCAD foi usado para a medida da área (A), do comprimento da rede de drenagem $(\mathrm{Cr})$, do perímetro (P), do maior comprimento $(\mathrm{C})$ e da maior largura $(\mathrm{L})$ de cada microbacia. A comparação desses foi realizado numa planilha eletrônica do Excel.

A descrição das características morfométricas dimensionais, do padrão de drenagem e do relevo, as fórmulas e as fontes das variáveis em estudo foram realizadas de acordo com Horton (1945), Smith (1950), Schumm (1956), Strahler (1952, 1958) e França (1968).

\section{Resultados}

Segundo Christofoletti (1974), a área de estudo se caracteriza por ser uma drenagem fluvial continua até o oceano (exorreica), formando cursos d'água que coincidem com a inclinação principal das camadas rochosas (consequentes), assemelhando-se a configuração de uma árvore (dendritica). Segundo Strahler (1957) é classificada como microbacia de $4^{\mathrm{a}}$ ordem, com 2 microbacias de $3^{\mathrm{a}}$ ordem, 7 microbacias de $2^{\mathrm{a}}$ ordem e 20 microbacias de $1^{\mathrm{a}}$ ordem, totalizando 30 microbacias.

A medida de campo mostrou que as nascentes 4 e 6 (Figura 1) não foram contempladas pela cartografia oficial. Isso alterou o comprimento total da rede de drenagem, cujo aumento no número total de microbacias acabou reduzindo a metragem de curso d'água por microbacia, e consequentemente, o comprimento médio da rede de drenagem.

Com isso, o número e as áreas das microbacias de $1^{\mathrm{a}}$ e $2^{\mathrm{a}}$ ordens foram alteradas, porém, sem alterar o número e a área das microbacias de $3^{\mathrm{a}}$ e $4^{\mathrm{a}}$ ordens. Isso se deve à inserção de uma nova microbacia de $1^{a}$ ordem, tornando-a uma microbacia de $2^{a}$ ordem de grandeza, num ponto mais próximo à nascente, diminuindo sua área inicial.

O baixo valor médio do fator de forma (Tabela 1) para a microbacia de $4^{\mathrm{a}}$ ordem define uma bacia mais alongada, que segundo Rodrigues (2004), diminui o risco de concentração rápida das águas das chuvas para o canal principal, diminuindo a possibilidade de ocorrência de enchentes.

Os valores médios do índice de compacidade e do índice de circularidade também mostram que a microbacia tem forma mais alongada que circular. Tonello et al (2006) cita que a forma da microbacia é importante na determinação do tempo de concentração, ou seja, o 
tempo necessário para que toda a bacia contribua para a sua saída após uma precipitação e que, quanto maior o tempo de concentração menor a vazão máxima de enchente.

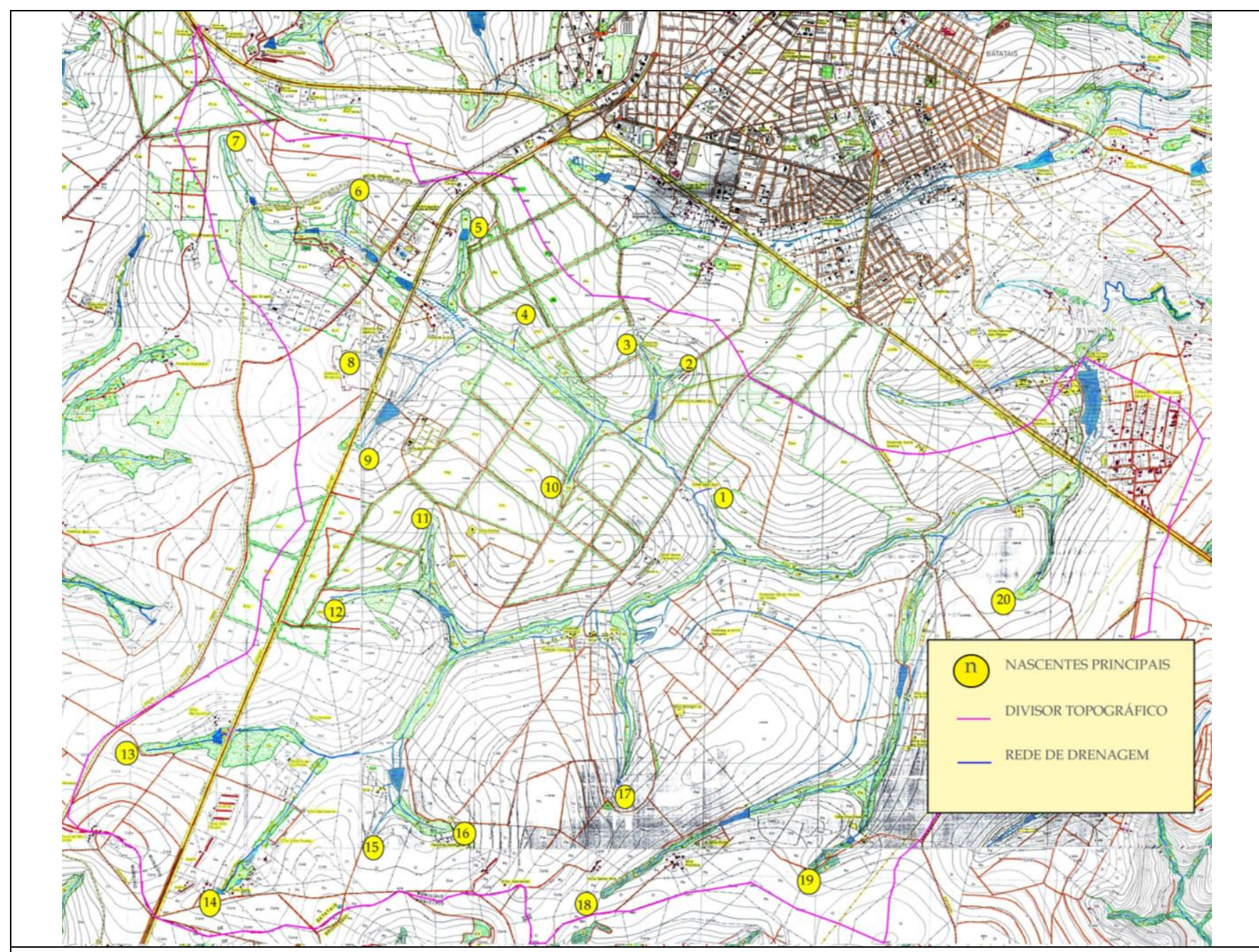

Figura 1. Microbacias avaliadas na Carta do Brasil - Instituto Geográfico e Cartográfico (IGC), Escala 1:10.000 (SÃO PAULO, 1992).

Tabela 1 - Características dimensionais da microbacia do Córrego da Cachoeira, Batatais/SP.

\begin{tabular}{lcc}
\hline \multicolumn{1}{c}{ Microbacia de $4^{\mathrm{a}}$ ordem } & IGC & IGC campo \\
\hline Área de drenagem $\left(\mathrm{km}^{2}\right)$ & 40,69 & 40,69 \\
Perímetro $(\mathrm{km})$ & 33,83 & 33,83 \\
Comprimento $(\mathrm{km})>$ & 9,46 & 9,46 \\
Largura $(\mathrm{km})>$ & 10,01 & 10,01 \\
Comprimento Total da rede de drenagem $(\mathrm{km})$ & 34,97 & 35,54 \\
Comprimento médio da rede de drenagem $(\mathrm{m})$ & 1344,89 & 1184,55 \\
Coeficiente de Compacidade Kc & 1,48 & 1,48 \\
Fator de forma Ff & 0,46 & 0,46 \\
Índice de Circularidade IC & 0,45 & 0,45 \\
\hline
\end{tabular}

Esses fatos contribuíram para o aumento no número de cursos d'água em menor espaço territorial, resultando na redução da relação de bifurcação e da relação do 
comprimento médio das microbacias de $1^{\mathrm{a}}$ ordem em relação às microbacias de $2^{\mathrm{a}}$ ordem (Tabela 2). Em compensação houve o aumento do valor desses parâmetros na relação entre as microbacias de $2^{\mathrm{a}}$ ordem com as de $3^{\mathrm{a}}$ ordem, devido ao aumento no número das microbacias de $2^{\mathrm{a}}$ ordem.

Tabela 2 - Razão de bifurcação e Relação do comprimento médio entre cada ordem da microbacia do Córrego da Cachoeira, Batatais/SP.

\begin{tabular}{lcccc}
\hline Características & Escala & $1 / 2$ & $2 / 3$ & $3 / 4$ \\
\hline Razão de bifurcação & IGC & 3,60 & 2,50 & 2,00 \\
& IGC campo & 2,86 & 3,50 & 2,00 \\
\hline Relação do comprimento médio & IGC & 4,29 & 2,55 & 2,97 \\
& IGC campo & 3,31 & 4,09 & 2,94 \\
\hline IGC - escala 1:10.000; IGC campo - Medida de Campo
\end{tabular}

Analisando as características do padrão de drenagem (Tabela 3), observamos que a densidade de drenagem é considerada baixa (VILLELA e MATTOS, 1975), fato geralmente associado a regiões de rochas permeáveis (TONELLO et al, 2006), que facilitam a infiltração da água no solo. A maior infiltração de água no solo diminui o escoamento superficial e estabelece maior relação entre infiltração e deflúvio, o que reduz o risco à erosão e, mais uma vez, à degradação ambiental.

Tabela 3 - Características do padrão de drenagem da microbacia do Córrego da Cachoeira, Batatais/SP.

\begin{tabular}{lcc}
\hline Características & IGC & IGC campo \\
\hline Densidade de drenagem & 0,86 & 0,87 \\
Freqüência de rios & 0,64 & 0,74 \\
Razão de textura & 0,77 & 0,89 \\
Extensão de percurso superficial & 0,58 & 0,57 \\
Coeficiente de manutenção & 1163,83 & 1145,18 \\
\hline IGC - escala 1:10.000; IGC campo - Medida de Campo & &
\end{tabular}

Os valores da frequência de rios e da razão de textura (Tabela 3) aumentam devido ao aumento do número de compartimentos hidrológicos. Os valores do coeficiente de manutenção e da extensão de percurso superficial indicam que a região de estudo apresenta solos mais permeáveis. Santos e Sobreira (2008), estudando regiões de baixa capacidade de infiltração de água obtiveram valores de 178,2 para o coeficiente de manutenção e de 89,3 para a extensão de percurso superficial.

A baixa amplitude altimétrica (Tabela 4) resultou em baixos valores para a razão de relevo e para a razão de relevo relativo, sugerindo uma microbacia com relevo relativamente suave.

Tabela 4 - Características do relevo da microbacia do Córrego da Cachoeira, Batatais/SP.

\begin{tabular}{lcc}
\hline Características & IGC & IGC campo \\
\hline Maior Altitude & 908 & 908 \\
Menor Altitude & 800 & 800 \\
Amplitude Altimétrica & 108 & 108 \\
Razão de relevo & 0,0114 & 0,0114 \\
Razão de relevo relativo & 0,0032 & 0,0032 \\
\hline IGC - escala 1:10.000; IGC campo - Medida de Campo
\end{tabular}




\section{Conclusões}

A verdade de campo demonstrou que existem nascentes principais não contempladas na cartografia oficial;

O baixo valor do fator de forma definiu uma bacia mais alongada que circular, onde o tempo de concentração aumenta e a susceptibilidade à enchentes mais acentuadas diminui.

\section{Referencias Bibliográficas}

CAMARGO, M. N. E.; KAUFMANN, J. N. Sistema Brasileiro de Classificação de Solos. Boletim Informativo da Sociedade Brasileira de Ciência do Solo. Campinas, v.12, n. ${ }^{\circ}$ 1. p 11-13. 1987.

CHRISTOFOLETTI, A. Geomorfologia. São Paulo, Editora Blücher, Editora da Universidade de São Paulo. 1974. 149p.

FRANÇA, G. V. Interpretação fotográfica de bacias e de rede de drenagem aplicada a solos da região de Piracicaba - SP. 1968. 151 p. Tese (Doutorado em Solos e Nutrição de Plantas) - Escola Superior de Agricultura "Luiz de Queiroz", Universidade de São Paulo, Piracicaba. 1968.

FREIRE, O. Solos das regiões tropicais. Botucatu: FEPAF - Fundação de Estudos e Pesquisas Agrícolas e Florestais. 2006. p. 92. ISBN 85-98187-03-8

HORTON, R.E. Erosional development of streams and their drainage basins: hydrophysical approach to quantitative morphology. Geological Society of America Bulletin. Colorado, v. 56, n. 3. p 275-370. 1945.

RODRIGUES, V. A. Aspectos da sustentabilidade das microbacias hidrográficas. In: Workshop em Manejo de Bacias Hidrográficas. UNESP, FCA, Botucatu. 2003. p. 70-82.

RODRIGUES, V. A. Morfometria e mata ciliar da microbacia hidrográfica. In: RODRIGUES, V. A. STARZYNSKI, R. Workshop em manejo de bacias hidrográficas. Departamento de Recursos Naturais, Faculdade de Ciências Agronômicas, Universidade Estadual Paulista. Botucatu, SP. 2004. p. 7-18.

SANTOS, C. A.; SOBREIRA, F. G. Análise morfométrica como subsídio ao zoneamento territorial: o caso das bacias do Córrego Carioca, Córrego do Bação e Ribeirão Carioca na região do Alto Rio das Velhas MG. Revista Escola de Minas. Ouro Preto, volume 61, fascículo 1. p. 77-85. 2008.

SÃO PAULO. Secretaria da Indústria, Comércio, Ciência e Tecnologia. Instituto de Pesquisas Tecnológicas do Estado de São Paulo - IPT. Mapa Geomorfológico do Estado de São Paulo. Boletim Técnico Científico. São Paulo, v. 1. 1981.

SÃO PAULO. Secretaria de Planejamento e Gestão. Coordenadoria de Planejamento Regional. Instituto Geográfico e Cartográfico. Plano Cartográfico do Estado de São Paulo. São Paulo. Escala 1:10.000. 1992.

SCHUMM, S. A. Evolution of drainage systems and slopes in bedlands at Perth Amboy. Bulletin Geological Society America. New Jersey, v. 67. p. 597-646. 1956.

SMITH, K. G. Standards for grading texture of erosional topography. American Journal Science. New Haven, v. 248. p. 655-668. 1950.

STRAHLER, A. N. Dimensional analysis applied to fluvially eroded landforms. Bulletin Geological Society America. Colorado, v. 69. p. 279-300. 1958.

STRAHLER, A. N. Dynamic basis of geomorphology. Bulletin Geological Society America. Colorado, v. 63. p. 923-938. 1952.

STRAHLER, A. N. Quantitative analysis of watershed geomorphology. Transactions of American Geophysical Union. New Haven, v. 38. p 913-920. 1957.

VILLELA, S. M.; MATOS, A. Hidrologia aplicada. São Paulo: McGraw-Hill do Brasil, 1975. 245p.

TONELLO, K. C. et al. Morfometria da bacia hidrográfica da cachoeira das pombas, Guanhães - M.G. Revista Árvore. Viçosa, v. 30, n. 5. p. 849-857. 2006. 